\title{
High prevalence of antibiotic resistance among bacteria isolated from pregnant women with asymptomatic urinary tract infections in Dar es Salaam,Tanzania
}

\author{
*Mwambete KD. ${ }^{1}$, Malaba P. $^{2}$
}

\begin{abstract}
Objectives: Urinary tract infections (UTI) are among the major causes of morbidity in pregnant women because of physiological changes during pregnancy and, if unattended to may cause severe complications to mother and foetus. Asymptomatic urinary tract infections (AUTI) can be important predictors for pathogenesis of UTI. This study aimed to determine the prevalence of AUTI among pregnant women using rapid dipstick and routine culture methods to assess antimicrobial resistance patterns of isolated pathogens.
\end{abstract}

Methods: This was a cross-sectional study. Using non-probability convenience sampling technique, a total of 202 pregnant women attending Antinatal Care (ANC) were recruited. Mid-stream urine was collected and subjected to rapid dipstick and urine culture media. Antibacterial susceptibility tests were conducted against the bacteria. Risk factors for AUTI and demographic data were obtained using pretested questionnaire. Data were analyzed using SPSS Vs. 20 software package.

Results: Of the 202 pregnant women, 47 (23.3\%) had AUTI. Age ranged from 15-45 years with a median of $26 \pm 3.0$ years. The main uropathogens were Escherichia coli (E.coli) 22(46.8\%). The dipstick test had sensitivity of $79.2 \%$ and specificity of $63.6 \%$. Seventy-three percent of $E$. coli were resistant to ampicillin and $86 \%$ to erythromycin. The prevalence rate of antibiotic resistance among the isolated bacteria ranged from 73 to $100 \%$.

Conclusion: Prevalent uropathogens among bacteria isolated from pregnant women with AUTI were Escherichia coli and Klebsiella pneumoniae. High antibiotic resistance were observed among the bacteria. About $23 \%$ of pregnant women had AUTI. We advocate for regular culture of urine to be performed because of the lower sensitivity of dipstick test.

Key-words: Pregnancy, antibiotic resistance, uropathogenic bacteria

*Correspondence author: Prof.Mwambete K.D.; Email:kmwambete@muhas.ac.tz OR kenyda@yahoo.com

${ }^{1}$ Department of Pharmaceutical Microbiology, School of Pharmacy, Muhimbili University of Health \& Allied Sciences, Dar es Salaam, Tanzania.

${ }^{2}$ Department of Pharmacy, Amana Regional Referral Hospital, Dar es Salaam,Tanzania.

Research Journal of Health Sciences subscribed to terms and conditions of Open Access publication. Articles are distributed under the terms of Creative Commons Licence (CC BY-NC-ND 4.0). (http://creativecommons.org/licences/by-nc-nd/4.0).

http://dx.doi.org/10.4314/rejhs.v5i2.2 


\title{
Haute prévalence de la résistance aux antibiotiques chez les bactéries isolées de femmes enceintes atteintes d'infections urinaires asymptomatiques à Dar es-Salaam, en Tanzanie
}

\author{
*Mwambete KD. ${ }^{1}$, Malaba P. $^{2}$
}

\begin{abstract}
Resume
Objectifs: Les infections des voies urinaires (UTI) sont parmi les principales causes de morbidité chez les femmes enceintes à cause des changements physiologiques pendant la grossesse et, si elle n'est pas surveillée, peut causer de graves complications à la mère et au foetus. Les infections asymptomatiques des voies urinaires (AUTI) peuvent être des prédicteurs importants pour la pathogenèse de l'UTI. Cette étude visait à déterminer la prévalence de l'AUTI chez les femmes enceintes à l'aide d'échantillons rapides et de méthodes de culture de routine pour évaluer les caractéristiques de résistance aux antimicrobiens des pathogènes isolés.
\end{abstract}

Méthodes: il s'agissait d'une étude transversale. En utilisant une technique d'échantillonnage sans probabilité, un total de 202 femmes enceintes participant à l'ANC ont été recrutés. L'urine à mi-parcours a été recueillie et soumise à une jauge rapide et à des milieux de culture d'urine. Des tests de sensibilité antibactériens ont été effectués contre la bactérie. Les facteurs de risque pour l'AUTI et les données démographiques ont été obtenus en utilisant un questionnaire prétesté. Les données ont été analysées à l'aide du logiciel SPSS Vs20.0.

Résultats: Parmi les 202 femmes enceintes, 47 (23,3\%) avaient une AUTI. L'âge variait de 15 à 45 ans avec une médiane de $26 \pm 3,0$ ans. Les principaux uropathogènes étaient Escherichia coli (E. coli) 22 (46,8\%). Le test de la jauge a eu une sensibilité de 79,2\% et une spécificité de 63,6\%. Soixante-treize pour cent de E. coli étaient résistants à l'ampicilline et $86 \%$ à l'érythromycine. Le taux de prévalence de la résistance aux antibiotiques chez les bactéries isolées variait de 73 à $100 \%$.

Conclusion: Les uropathogènes prévalents parmi les bactéries isolées de femmes enceintes avec AUTI étaient Escherichia coli et Klebsiella pneumoniae. Une forte résistance aux antibiotiques a été observée chez les bactéries. Environ 23\% des femmes enceintes avaient une OAU. Nous préconisons une culture régulière de l'urine à effectuer en raison de la sensibilité plus faible du test de la jauge.

Mots-clés: Grossesse, résistance aux antibiotiques, bactéries uropathogènes

\footnotetext{
*Auteur de la correspondance: Prof.Mwambete K.D.; Email: kmwambete@muhas.ac.tz OR kenyda@yahoo.com

${ }^{1}$ Department of Pharmaceutical Microbiology, School of Pharmacy, Muhimbili University of Health \& Allied Sciences, Dar es Salaam, Tanzania.

${ }^{2}$ Department of Pharmacy, Amana Regional Referral Hospital, Dar es Salaam,Tanzania.
} 


\section{INTRODUCTION}

Over $10 \%$ of hospital visits by women are due to urinary tract infections (UTI) particularly during pregnancy (1), which can manifest as asymptomatic urinary tract infections (AUTI) or symptomatic UTI (2). Pregnant women are at increased risk of acquiring UTI with increase in gestation period, from $0.8 \%$ in the $12^{\text {th }}$ week to $2 \%$ at the end of pregnancy, which could be due to ureteral dilatation (3-5). Other most frequent physiological changes during pregnancy include increased bladder volume and reduced bladder tone accompanied with ureteral muscle tone relaxation. These contribute to increased urinary stasis and ureterovesical reflux $(5,6)$. Besides, majority of pregnant women develop glycosuria that also encourages bacterial growth in the urine $(7,8)$.

Escherichia coli, Klebsiella and Enterobacter are found to be among the most frequent causes of UTI, though other gram positive bacteria have been reported (9). Ascending UTI, premature birth and foetal mortality are the frequent complications owing to UTI during pregnancy (10-12). Similarly, one recent study has associated UTI during pregnancy and early occurrence of autonomic nervous system disorders in new-borns (13).

Over the past 5 years, no study had been conducted in Dar Es Salaam to investigate the prevalence rate of UTI during pregnancy and its associated complications. Therefore, there are insufficient local data on AUTI among pregnant women in Dar Es Salaam. Moreover, data on prevalence rates of UTI in Tanzania vary significantly from one administrative or geographical area to another ranging from $14 \%$ to $21 \%(9,14)$. Amoxicillin constitutes the first line antibiotic therapy for treatment of UTI during pregnancy as per the Tanzania Standard Treatment Guidelines (STG). The second line therapy comprises nitrofurantoin and amoxicillin/clavulanic acid. In case of penicillin sensitive women; erythromycin or azithromycin are the drugs of choice (15). On the other hand, antibacterial susceptibility patterns on newly introduced antibacterial agents such as erythromycin and azithromycin are not well documented. Therefore, data on the prevalence of AUTI during pregnancy and antimicrobial resistance patterns of the pathogens in Tanzania is inadequate. Moreover, early detection and treatment of UTI were proposed in the millennium development goals for health as one of the most cost-effective strategies to reduce incidences of UTI and the associated complications in pregnant women and neonates, particularly in developing countries (16-18). Consequently, this study aimed to identify the current prevalence rates of AUTI among pregnant women attending antenatal clinics (ANC) in Dar Es Salaam and antimicrobial resistance patterns of the isolated uropathogenic bacteria. The acronym AUTI will be used interchangeably with significant presence of bacteria in urine (significant bacteriuria), throughout this paper.

\section{MATERIALS AND METHODS Study setting/population}

This study involved pregnant women attending ANC in Dar Es Salaam City, which is the country's most populous city with over 5 million habitants. The study was conducted at two public health centers viz. Mnazi Mmoja and Magomeni situated in Ilala and Kinondoni Municipalities respectively. The participants include pregnant women attending ANC. The exclusion criteria include symptomatic pregnant women with febrile symptoms including dysuria, urinary hesitancy, incontinence, incomplete voiding and individuals on antibiotic therapy during the study period.

\section{Study design and sampling}

A descriptive cross-sectional study was conducted at the two health centers between January and March 2015. The non-probability convenience sampling technique was employed to recruit a total of 202 pregnant women by using the formula:

$$
\mathrm{n}=\underline{\mathrm{Z}^{2}} \frac{\mathrm{p}(1-\mathrm{p})}{\mathrm{e}^{2}}
$$

Where: $\mathrm{z}=\mathrm{Z}$ score for $95 \%$ confidence interval $=1.96, \mathrm{p}=$ prevalence, $\mathrm{e}=$ tolerable error $=5 \%$. A proportion of $20 \%$ was used as $\mathrm{p}(14)$.

\section{Data collection}

With the aid of a pretested questionnaire, demographic data including age, education level, gravidity and gestational age of pregnancy were collected. Pregnant women were also interviewed on awareness of UTI and its complications during pregnancy as well as on other risk factors for UTI. Each participant was provided with sterile container, instructed on the correct mode of self-collection of MSU(write in full before acronym) sample and the importance of a clean catch of MSU. Aliquots of the collected 
samples were microscopically examined for bacteria, pus and ova. Rapid urine dipstick test was performed instantly on receipt of the MSU for immediate medical intervention for pregnant women with significant AUTI. Using a calibrated loop $(10 \mu 1)$, urine samples were inoculated on Cysteine lactose electrolyte deficient agar (CLED) and incubated overnight. All urine samples that were not cultured within 2 hours were stored at $4^{\circ} \mathrm{C}$.

\section{Isolation and identification of bacteria}

Colony counts producing bacterial growths of $\geq 10^{5} \mathrm{cfu} / \mathrm{ml}$ were considered significant. Bacteria were isolated and identified based on pure colony morphology and biochemical tests (19). Urine samples yielding non-significant or/and mixed growths did not have the test repeated.

\section{Antibacterial susceptibility testing}

The Kirby-Bauer disk diffusion method was used for antibacterial susceptibility testing of the isolated bacteria on Muller-Hinton agar plates (LAB-M, Lancashire, UK). Seven antibiotics commonly used for treatment of UTI during pregnancy as per the standard treatment guidelines (STG) of Tanzania were used for this purpose (15). These antibiotics were represented by commercially available sensitivity antibiotic discs namely ampicillin (AP10) discs were used instead), amoxicillin-clavulanic acid (AUG30), nitrofurantoin (NI30), erythromycin (E15), azithromycin (ATH15), ceftriaxone (CRO30) and gentamicin (GM10) (Mast Group Limited, Merseyside, UK). Ceftriaxone and gentamicin were also included as most of the interviewed pregnant women claimed to had previously used them for treatment of UTI. Results were interpreted as susceptible (S), intermediate (I) and resistant $(\mathrm{R})$ as per the Clinical and Laboratory Standard Institute guidelines (20).

\section{Ethical consideration}

The present study was approved by the Research and Publication Committee of the Muhimbili University of Health and Allied Sciences, Dar Es Salaam, Tanzania, while written approval letters were obtained from District Medical Officers of the two districts/municipalities. Informed written and verbal consents were obtained from participants before enrollment in the study. For participants under the age of 18 years, consent was also sought from their parents/guardians. The personal identifiers were removed before data entry and analysis. Results were only disclosed to the willing individual participants and relevant health personnel for medical/treatment purposes.

\section{Data Management}

Data were coded and analysed by using the statistical package for social sciences (SPSS version 20) software. Analysis of the prevalence rates of AUTI, antimicrobial resistance (based on zones of inhibition exerted by each tested antibiotic on isolated bacteria) and other investigated parameters were performed. The Dunnett's test (two-sided) was used to compare the significance of differences between zones of inhibition produced by each uropathogenic bacteria to that of control bacterial strains. Univariate analysis of variance, cross-tabulation (Chi-squares) and logistic regression were used for the analysis of various variables such as risk factors for AUTI during pregnancy. Differences among the tested variables were considered significant when $\mathrm{p}<0.05$.

\section{RESULTS}

\section{Demographic characteristics of the study population}

A total of 202 pregnant women from 50 different localities of Dar Es Salaam City were recruited in this study, their ages ranged from 1545 years with a median of $26+$ years. Slightly more than half $(56.9 \%)$ of the participants were of ages between 20 and 29 years. Over one third $(36 \%)$ of participants were primigravida. One hundred and one $(50 \%)$ participants had primary education. Presence of AUTI among the pregnant women, revealed no direct association with age, education level, gestation age or gravidity (Table 1).

\section{Prevalence of UTI among the study pregnant women}

Mid-stream urine (MSU) sample was collected from each participant and subjected to microbiological analysis. About 23\% (47) of MSU samples showed significant AUTI ( $\geq$ $10^{5} \mathrm{cfu} / \mathrm{ml}$ ) as shown in Tables 1 and 2 . Out of 47 pregnant women with significant AUTI, 21.3\% $(n=10)$ and $70.2 \%(n=33)$ were in their first and second trimesters respectively (Table 1). The most frequently isolated bacteria was Eschericia coli $(46.8 \%)$ while the least frequently isolated was Pseudomonas aeruginosa (2.1\%) - Table 2. When results from the MSU culture were compared to those obtained from the rapid 
dipstick test; the latter had a sensitivity of $79.2 \%$ and specificity of $63.6 \%$ with positive and negative predictive values of $40.45 \%$ and $90.7 \%$ respectively. The urine culture tests yielded positive results in $23.3 \%$ of the tested MSU samples, while the dipstick test produced $9.3 \%$ false negative results. Odds of the standard culture media (aerobic bacterial counts) yielding positive results was 6.083 higher than that of dipstick test $(\mathrm{p}<0.01)$.

\section{Antimicrobial susceptibility profiling}

Our findings revealed high rates of antibacterial resistance among the isolated bacteria, ranging from as high as $86.4 \%$ to $100 \%$ and $72 \%$ to $100 \%$ against erythromycin and ampicillin respectively as indicated in Table 3 . Most of the tested E. coli were resistant to ampicillin (72.7\%) and erythromycin (86.4\%), while only a few exhibited resistance to nitrofurantoin (18.2\%) and azithromycin (36.4\%). Klebsiella pneumoniae exhibited a high antibacterial resistance against erythromycin (94.7\%) while low resistance was observed against gentamicin $(5.3 \%)$. Three species of bacteria (Staphylococcus aureus, Proteus species and Pseudomonas aeruginosa) were sensitive to nitrofurantoin, but $100 \%$ resistant to ampicillin and erythromycin. Azithromycin, ceftriaxone and gentamicin were relatively effective against most of the isolated bacteria, particularly Pseudomonas aeruginosa and Proteus species. None of the isolates were sensitive to all tested antibiotics (Table 3 ).

\section{Analysis of some risk factors for AUTI in pregnancy}

There was no association between the prevalence of AUTI and gestation age $(\mathrm{p}=$ $0.417)$, educational level $(\mathrm{p}=0.383)$ and gravidity $(p=0.873)$ of the participants. Crosstabulation (Chi-squares test) showed no significant association between the prevalence rates of AUTI and the pregnant women's awareness of the UTI-associated complications during pregnancy $(p=0.119)$, Table 4 . However, those who had ever experienced dysuria were 4.68 times more likely to contract AUTI $(p<0.01)$. The odds for pregnant women who had ever experienced febrile episodes to yield significant bacterial growth (AUTI) were 4.34 higher than those who had never experienced $(p<0.01)$. Nineteen and 23 respondents could not respond to the questions on whether they were aware of the UTI associated complications or /and whether they had ever suffered from UTI respectively (Table 4).

\section{DISCUSSION}

The study revealed significant AUTI among the pregnant women in the surveyed health centers, with a prevalence rate of $23.3 \%$. The prevalence rates of $6.1-10.9 \%$ have been reported from Iran, $7.3 \%$ in Ghana and $13 \%-21 \%$ from Tanzania between 2009 and 2010(9,21). A higher rate $(55 \%)$ was reported from Nigeria (22). One previous study indicated that the prevalence rate might be even higher in resources-limited countries, particularly among persons of lower socioeconomic status (23). However, most of the observed differences in prevalence rates of AUTI, might be due to microbiological techniques that were employed. The authors agree with a previous finding (9) that dipstick test should also be used in conjunction with other urinalysis techniques to avoid false negative results, since the former has lower sensitivity $(79.2 \%)$ and specificity $(63.6 \%)$.

In conformity with another previous study (21), Escherichia coli and Klebsiella pneumoniae were the predominantly isolated microorganisms. The other isolated bacteria include $S$. aureus, $P$. aeruginosa and Proteus species that are less common causes of UTI, unless if introduced iatrogenically $(17,24)$. It is now recognized that despite the geographical variability of uropathogens, the predominant microorganisms are Enterobacteriaceae and especially Escherichia coli and Enterobacter species $(22,26)$.

All isolated E. coli were sensitive to gentamicin, and only a few exhibited resistance to ceftriaxone $(4.5 \%)$, nitrofurantoin $(18.2 \%)$ and azithromycin (36.4\%). Contrary to our findings, Oladeinde (22) found that nitrofurantoin and amoxicillin had poor activity against most of the uropathogenic bacteria. About $94.7 \%, 78.9 \%$ and $73.7 \%$ of Klebsiella isolates exhibited resistance to erythromycin, amoxicillin-clavulanic acid and ampicillin respectively; notwithstanding being some of the antibiotics of choice for treatment of UTI during pregnancy in Tanzania (15). The single isolate of $P$. aeruginosa showed 100\% resistance to erythromycin, amoxicillinclavulanate and ampicillin. Gentamicin has proved to be still effective for treatment of AUTI in pregnant womeneven though it is known to be nephrotoxic (27). Therefore, gentamicin should be used whenever clinically indicated. In several resource limited countries like Tanzania, there is 
limited availability of medications $(28,29)$, thus obliging prescribers to prescribe whatever is available. The fact that only $57 \%$ of tested antibiotics exerted significant antibacterial activities against the uropathogenic bacteria, shows that there is no universal remedy for treatment of UTI during pregnancy.

A number of factors have been ascribed to the high prevalence of AUTI during pregnancy, which include parity, age, previous medical history of UTI, and socio-economic status among others $(4,22)$. The present study shows that level of education, age, gravidity, gestational age and previous history of UTI are independently associated with AUTI, which is in concordance with previous study by Masinde et al.(9). A statistically significant association was observed between an individual patient's susceptibility to UTI with dysuria and febrile episodes as previously observed (2). It was observed that most of the pregnant women with significant AUTI were in their first and second trimesters with a prevalence of $33.3 \%$ and $24.3 \%$ respectively. Presumably this is because a number of pregnant women register at ANC during such periods for ascertaining their pregnancy or/and delivery period.

\section{CONCLUSION}

This study shows a relatively higher prevalence rate of AUTI (23\%) among pregnant women in Dar Es Salaaam as compared to that of previous studies $(21 \%)$. High antibiotic resistance rates (73-100\%) were exhibited by the isolated uropathogenic bacteria. The predominant microorganisms associated with the infection were $E$. coli and $K$. peumoniae. Majority of the isolated bacteria were resistant to erythromycin, amoxicillin-clavulanic acid and ampicillin. Given these observations, we suggest improvement of awareness on local antimicrobial resistance patterns among prescribers in order to facilitate proper antibiotic prescribing. The study also highlights the need for ANC personnel to educate pregnant women on the potential risks of UTI and how to prevent it during their visits to ANC. The authors recommend performing routine urine culture because of the revealed lower sensitivity of rapid dipstick test.

Acknowledgments: The authors appreciate the financial support of The Ministry of Education and Vocational Training of Tanzania, MUHAS Ethical Committee and Ilala and Kinondoni Municipal Authorities for their permissions to conduct this study at their respective health centers.

Conflict of interest: The authors declare no conflict of interest.

\section{REFERENCES}

1. Matulay JT, Mlynarczyk CM, Cooper KL. Urinary Tract Infections in Women: Pathogenesis, Diagnosis, and Management. Curr Bladder Dysfunct Rep. 2016;11:53-60.

2. Gebäck C, Hansson S, Martinell J, Milsom I, Sandberg T, Jodal U. Obstetrical outcome in women with urinary tract infections in childhood. Acta Obstet Gynecol Scand. 2016; 95:452-457.

3. Matuszkiewicz-Rowińska J, Małyszko J, Wieliczko M. Urinary tract infections in pregnancy: old and new unresolved diagnostic and therapeutic problems. Arch Med Sci. 2015 Mar 16;11(1):67-77.

4. Curtis GB, Schuler J. Your pregnancy week by week. Da Capo Press; 2016 May 24.

5. Salam MA, Ullah AA. Etiology of flaccid type of neuropathic bladder. Principles and Practice of Urology. $2^{\text {nd }}$ ed. Jaypee Brothers Medical Publishers,ed. 2013;1:406-410.

6. Welch TR. Functional Symptoms in Nephrology: Keeping It In and Letting It Out. In Functional Symptoms in Pediatric Disease. Springer New York. 2014;87-95.

7. Haider G, Zehra N, Munir AA, Haider A. Risk factors of urinary tract infection in pregnancy. $\mathrm{J}$ Pak Med Assoc. 2010;60:213.

8. Mardi TG, Lutfi MF. Risk factors for gestational diabetes mellitus in Sudanese pregnant women. Int J Med Biomed Res. 2013;1:79-84.

9. Masinde A, Gumodoka B, Kilonzo A, Mshana SE. Prevalence of urinary tract infection among pregnant women at Bugando Medical Centre,Mwanza,Tanzania. Tanzan J Health Res. 2009;11:343.

10. Chan GJ, Lee AC, Baqui AH, Tan J, Black RE. Prevalence of early-onset neonatal infection among newborns of mothers with bacterial infection or colonization: a systematic review and meta-analysis. BMC infectious diseases. 2015;15:1.

11. Leviton A, Allred EN, Kuban KC, O'Shea TM, Paneth N, Onderdonk AB, Fichorova RN, Dammann O. The Development of Extremely Preterm Infants Born to Women Who Had Genitourinary Infections During Pregnancy. Am J Epidemiol. 2016;183:28-35.

12. Wilson $\mathrm{CB}$, Nizet V, Maldonado $\mathrm{Y}$, Remington 
JS, Klein JO. Remington and Klein's Infectious Diseases of the Fetus and Newborn Infant. Elsevier Health Sciences; 2015.

13. Hibbing ME, Conover MS, Hultgren SJ. The unexplored relationship between urinary tract infections and the autonomic nervous system. Auton Neurosci. 2016;31:200:29-34.

14. Kappas M, GroßU, Kelleher D. Global Health-A Challenge for Interdisciplinary Research. Göttingen International Health Network (GIHN) 2012;21:246-54.

15. The Standard Treatment Guidelines (STG) and the National Essential Medicine List for Tanzania (NEMLIT) 2013.

16. Gilbert NM, O'Brien VP, Hultgren S, Macones G, Lewis WG, Lewis AL. Urinary tract infection as a preventable cause of pregnancy complications: opportunities, challenges, and a global call to action. Global Adv Health Med. 2013;2:59-69.

17. Flores-Mireles AL, Walker JN, Caparon M, Hultgren SJ. Urinary tract infections: epidemiology, mechanisms of infection and treatment options. Nature Rev Microbiol. 2015;13:269-84

18. Lakshmi ST, Thankam U, Jagadhamma P, Ushakumari A, Chellamma N, Hariharan SV. Risk factors for still birth: a hospital based case control study. Int J Reprod Contracept Obstet Gynecol. 2017;19;6(3):970-974.

19. Cheesbrough M. District Laboratory Practice in Tropical Countries. Part 2, Second Edition. Cambridge University Press The Edinburgh Building, Cambridge, CB2 8RU, UK; 2006.

20. Clinical Laboratories Standards Institute(CLSI). Performance Standards for Antimicrobial Susceptibility Testing; Sixteenth Informational Supplement. Wayne, PA: CLSI; 2006.

21. Moyo SJ, Aboud S, Kasubi M, Maselle SY. Bacterial isolates and drug susceptibility patterns of urinary tract infection among pregnant women at Muhimbili National Hospital in Tanzania.Tanzan J Health Res. 2010;12:4.

22. Oladeinde BH, Omoregie R, Oladeinde OB. Asymptomatic urinary tract infection among pregnant women receiving ante-natal care in a traditional birth home in Benin city, Nigeria. Ethiop J Health Sci. 2015; 25:3-8.

23. Emiru T, Beyene G, Tsegaye W, Melaku S. Associated risk factors of urinary tract infection among pregnant women at Felege Hiwot Referral Hospital, Bahir Dar, North West Ethiopia. BMC research notes. 2013;6:292.

24. Cole SJ, Records AR, Orr MW, Linden SB, Lee
VT. Catheter-associated urinary tract infection by Pseudomonas aeruginosa is mediated by exopolysaccharide-independent biofilms. Infect Immun. 2014;82:2048-58.

25. Guglietta A. Recurrent urinary tract infections in women: risk factors, etiology, pathogenesis and prophylaxis. Future Microbiol. 2017;12(3): 239246.

26. Singhal A, Sharma R, Jain M, Vyas L. Hospital and community isolates of uropathogens and their antibiotic sensitivity pattern from a tertiary care hospital in North West India. Ann Med Health Sci Res. 2015;4:51-6.

27. Reddy DC, Kumar GS, Swamy BV, Kumar KP. Protective effect of Cissampelos pareira linn. Extract on gentamicin-induced nephrotoxicity and oxidative damage in rats. Pharmacogn $\mathrm{J}$. 2014;6:59.

28. Strasser R, Kam SM, Regalado SM. Rural health care access and policy in developing countries. Annu RevPublic Health, 2016;37:395-412.

29. Khatib R, McKee M, Shannon H, Chow C, Rangarajan S, Teo K, Wei L, Mony P, Mohan V, Gupta R Kumar R. Availability and affordability of cardiovascular disease medicines and their effect on use in high-income, middle-income, and low-income countries: an analysis of the PURE study data. Lancet, 2016;387(10013):6169. 
Table 1: Demographic characteristics of pregnant women screened for bacteriuria (AUTI)

\begin{tabular}{lllll}
\hline $\begin{array}{l}\text { Investigated } \\
\text { Variables }\end{array}$ & No bacteriuria (\%) & $\begin{array}{l}\text { Significant } \\
\text { Bacteriuria (\%) }\end{array}$ & p-value \\
\hline Age group & $15-24$ & $57(28.2)$ & $17(8.4)$ & \\
& $25-34$ & $73(36.2)$ & $22(10.8)$ & \\
& $35-44$ & $25(11.9)$ & $8(4.0)$ & 0.80 \\
Education level & $=45$ & $1(0.5)$ & - & \\
& Informal & $3(1.5)$ & $2(1)$ & \\
& Primary & $75(37.1)$ & $26(12.9)$ & 0.415 \\
& Secondary & $65(32.2)$ & $18(8.9)$ & \\
Gravidity & College/University & $12(5.9)$ & $1(0.5)$ & 0.873 \\
& $1-2$ & $97(48)$ & $29(14.3)$ & \\
Gestation age & $3-4$ & $51(25.2)$ & $16(8.0)$ & \\
& $=5$ & $7(3.5)$ & $2(1.0)$ & 0.093 \\
\hline
\end{tabular}

Table 2: Aerobic bacterial counts of isolated uropathogenic bacteria

\begin{tabular}{lll}
\hline Bacterial isolates & $\begin{array}{l}\text { Number of pregnant women } \\
\text { with AUTI }\end{array}$ \\
\cline { 2 - 3 } & $=100000$ & $>100000$ \\
\hline None & $154(76.2)$ & $0(0.0)$ \\
E. coli & $1(0.5)$ & $21(10.4)$ \\
K. pneumonae & $0(0.0)$ & $19(9.4)$ \\
S. aureus & $0(0.0)$ & $4(2.0)$ \\
Proteus spp & $0(0.0)$ & $2(1.0)$ \\
P. aeruginosa & $0(0.0)$ & $1(0.5)$ \\
Total & $155(76.7)$ & $47(23.3)$ \\
\hline
\end{tabular}

Table 3: Prevalence rate of antibacterial resistance among isolated bacteria

\begin{tabular}{llllllll}
\hline \multirow{2}{*}{ Bacterium } & \multicolumn{3}{l}{ Rates $(\%)$ of antibacterial resistance } & & & \\
\cline { 2 - 8 } & AMP & AMC & NIT & ERY & AZI & CEF & GEN \\
\hline E. coli & 72.7 & 50 & 18.2 & 86.4 & 36.4 & 4.5 & - \\
K. pneumoniae & 73.7 & 78.9 & 36.8 & 94.7 & 36.8 & 10.5 & 5.3 \\
Staphylococcus aureus & 100 & 75 & - & 100 & 25 & 25 & 25 \\
Proteus spp & 100 & 50 & - & 100 & - & - & - \\
P. aeruginosa & 100 & 100 & - & 100 & - & - & - \\
\hline
\end{tabular}

Keys:AMP-ampicillin; AMC- amoxicillin-clavulanic acid; NIT-nitrofurantoin; ERY-erythromycin; AZIazithromycin; CEF-ceftriaxone; GEN-gentamicin. 
Table 4: Comparative analysis of risk factors for UTI during pregnancy

\begin{tabular}{|c|c|c|c|c|c|}
\hline \multirow[b]{2}{*}{ Variable } & & \multicolumn{2}{|c|}{ Urine culture results } & \multirow[t]{2}{*}{$X^{2}$ - value } & \multirow[t]{2}{*}{$P$-value } \\
\hline & & Positive & Negative & & \\
\hline \multirow{2}{*}{ Awareness on UTI } & Yes & 37 & 125 & \multirow{2}{*}{0.042} & \multirow{2}{*}{0.492} \\
\hline & No & 10 & 30 & & \\
\hline \multirow{2}{*}{$\begin{array}{l}\text { Knowledge } \\
\text { complications }\end{array}$} & Yes & 9 & 41 & \multirow[t]{2}{*}{1.862} & \multirow[t]{2}{*}{$0.119^{* 1}$} \\
\hline & No & 37 & 96 & & \\
\hline \multirow{2}{*}{ Ever suffered from UTI } & Yes & 32 & 87 & \multirow{2}{*}{1.022} & \multirow{2}{*}{$0.205^{* 2}$} \\
\hline & No & 12 & 48 & & \\
\hline \multirow[t]{2}{*}{ Had febrile episodes } & Yes & 23 & 26 & \multirow{2}{*}{19.182} & \multirow{2}{*}{0.001} \\
\hline & No & 24 & 126 & & \\
\hline \multirow{2}{*}{ Experienced dysuria } & Yes & 20 & 19 & \multirow{2}{*}{24.245} & \multirow{2}{*}{0.001} \\
\hline & No & 27 & 136 & & \\
\hline
\end{tabular}

$\left(*^{1}\right.$ and $\left.*^{2}\right)$ - a total of 21 and 23 respondents respectively, could not answer the questions. 